\title{
Formation of IT Competences of Future Mechanical Engineers
}

\author{
Dmitry V. Kurennov ${ }^{1 *}$, Natalia G. Ryzhkova ${ }^{1}$, Yury V. Serdyuk ${ }^{1}$, Maya L. Mayants ${ }^{1}$, and \\ Elena A. Timokhova ${ }^{1}$ \\ ${ }^{1}$ Ural Federal Unversity, 620002, Yekaterinburg, Russia
}

\begin{abstract}
Modern trends in the development of manufacturing industries impose new requirements on engineers. Due to the rapidly deepening trends in the digitalization of mechanical engineering, one of the main requirements for the successful professional activity of technical specialists is the possession of tools in the field of information technology. The work highlights the directions of development of mechanical engineering, which define IT-competences of engineers: automation of production and management of product life cycle, use of IT in design and production, growth of demand for "smart" machines. The prospects for the development of it infrastructure in the industry are outlined. On the basis of the analysis, a new content of the discipline "Information technologies in professional activity" of the basic part of engineering training aimed at the formation of popular it competencies is proposed. The main sections of the discipline are: the basics of algorithmization and programming, programming elements in Python, development and integration of software modules in automation systems, the basics of mathematical modeling, the basics of simulation. In the conditions of mass application of information technologies, transition to digital production, the use of the project method is seen as extremely promising in order to obtain a high-quality training result. The discipline provides for the implementation of the project, which includes tasks in a number of sections. Project assignments vary depending on the direction of training and the level of training of students. The structure of the content of the project work is presented in two versions: the work in the CAD-system, including the use of API; the execution of tasks in different sections with a division by level of complexity. It is proposed to divide the time allocated for the study of the discipline between sections on the basis of expert evaluation. Approbation for a number of areas of bachelor's training in the Department of mechanical engineering. Examples of projects implementation by students are given.
\end{abstract}

\section{Introduction}

Modern trends in the development of the machine-building industry strongly require changes in the basic training of students in the relevant technical areas.

\footnotetext{
* Corresponding author: d.v.kurennov@urfu.ru
} 
The usual methods of work conflict with the realities of engineering workplaces in the conditions of "Industry 4.0", as a result of which the transition from education to practice can be problematic for many engineers starting professional careers [1,2,3].

One of the main conditions for building the ability to ensure competitive production in the future is the integrated ownership of the necessary information technology tools.

\section{Directions of mechanical engineering development defining IT competence of engineers}

Demand for IT competences of specialists in mechanical engineering is determined by rapidly deepening trends of digitalization of this sector of production. The main trends are as follows.

\subsection{Manufacturing Automation and Product Lifecycle Management}

Mechanical engineering is one of those industries where automation projects have appeared quite a long time ago and are successfully developing at present. Automation is now subject to planning, accounting for material and commodity values, direct control of technological processes and many other internal business processes characteristic of machine-building enterprises.

At the moment, it's quite clear that it's not just marketing or corporate leadership that needs automation. The use of automation for the design of new products, the technology of their manufacture, the control of the products manufacture, warehouses and factory workshops, the supply service, sales, relations with partners, the possibility of servicing products after they leave the enterprise is the basis of product lifecycle management systems.

The use of information technology and automation of production processes, which were so high in the industry as compared to others, was primarily due to high competition. Improving and automating production methods and methods was a guarantee of success.

IT engineering automation of mechanical engineering projects are aimed, among other things, at obtaining prompt and up-to-date information, because without it is impossible to make any effective and timely decision, which is known to be a decisive factor in product lifecycle management. The use of information technologies in the automation of this production sector also contributed to the reduction of the cost of production and, in combination with the improvement of its quality, ultimately led to the optimization of production, which was the ultimate goal of the information technologies introduction into mechanical engineering.

Automation of production management has the following advantages: flexible structure, support for real-time decision making, simultaneous processes, integrated solution for the whole enterprise, fast implementation, open system and much more.

\subsection{Using IT in Design and Manufacturing}

It should be noted that automation and IT technologies are no less necessary at the stage of design and production than at the stage of finished products sale. The development and optimization of specialized software, which allows to 3D "see" any part, aggregate, not only on a static picture, but also in dynamics, opens up wide horizons for designers. What used to take years of painstaking work and calculations, today becomes available in a few minutes. 
Application of automation processes in production, provision of control over manufacturing progress and assembly of various assemblies to manufacture higher quality production [4]. The issue of increasing productivity and reducing the share of manual labor in modern enterprises is currently extremely acute.

\subsection{Growing demand for smart machines}

It is the desire of manufacturers to reduce the volume of manual work as much as possible, used in the enterprise, often becomes a factor that contributes to the increase of popularity of so-called "smart" machines.

Engineering technology has traditionally used the most advanced advances in science. The use of «smart» machines in mechanical engineering was far from new. Already in the 20th century, the industry used machines equipped with software numerical control, a variety of robots, many sites and workshops were fully or partially automated. Today, the issue of the use of "smart" machines, i.e. "intelligent" machines, in the production of "smart" machines is even more acute in mechanical engineering. The development of such "smart" mechanisms for mechanical engineering, controlled by modern computer technology, is developing at an increasing rate. The use of such machines will significantly increase productivity while reducing the costs associated with the so-called "human" factor $[5,6]$.

\subsection{Industry IT Infrastructure Prospects}

The development of IT infrastructure in mechanical engineering will be aimed primarily at increasing the intellectual capital of the enterprise. The use of automation will make it possible to further streamline the activities of all specialists of the enterprise, simplify the relationship between consumers and producers, and will become an effective basis for building an effective system of quality control over the products produced.

\section{Content of IT training}

On the basis of the analysis of trends and prospects of industry development, sections of the discipline "Information technologies in professional activity" (instead of the traditional course "Informatics") aimed at formation of the basic part of IT-competences of students bachelor 's degrees are proposed for study of the department "Mechanical Engineering" of the Institute of New Materials and Technologies. The Department implements educational programs of bachelor 's degree in the areas: "Mechanical Engineering", "Design and Technological Support of Mechanical Engineering Industries", "Technological Machines and Equipment", "Ground Transport and Technological Complexes", "Automation of Technological Processes and Industries", "Mechatronics and Robotics", "Information Systems and Technologies".

1. Basics of Algorithms development and Programming. The section involves the development and software implementation of general technical tasks using elements of the Pascal programming language in the Delphi, or Lazarus development environment.

2. Python Programming Elements. This section extends the task block implemented in the previous section. A modern engineer should be not just a user of application software, but be able to understand the software code, develop his own programs. The objectives of learning a second programming language are to shift the focus from learning a language as such to using a programming language as a tool to solve applications; familiarity with programming languages using different approaches to develop the ability to adapt to new 
programming languages; formation of ability to implement algorithm in different programming languages. The choice of the second language took into account its relevance, the availability of infrastructure around the language, which allows for rapid development of programs to solve tasks within the disciplines of specialization, support of existing packages of application software in the professional sphere of activity; free distribution, allowing students to use the programming language on home computers to work independently.

The Python programming language meets the above criteria due to its features. The demand for this language is evidenced by the content of programming courses on international educational platforms. The perspective of Python studies for technical training students is determined by its use as one of the main programming languages by a large number of employers [7].

A number of examples of Python applications for educational and professional activities $[8,9]$ for which there are ready-made libraries are presented in Fig. 1.

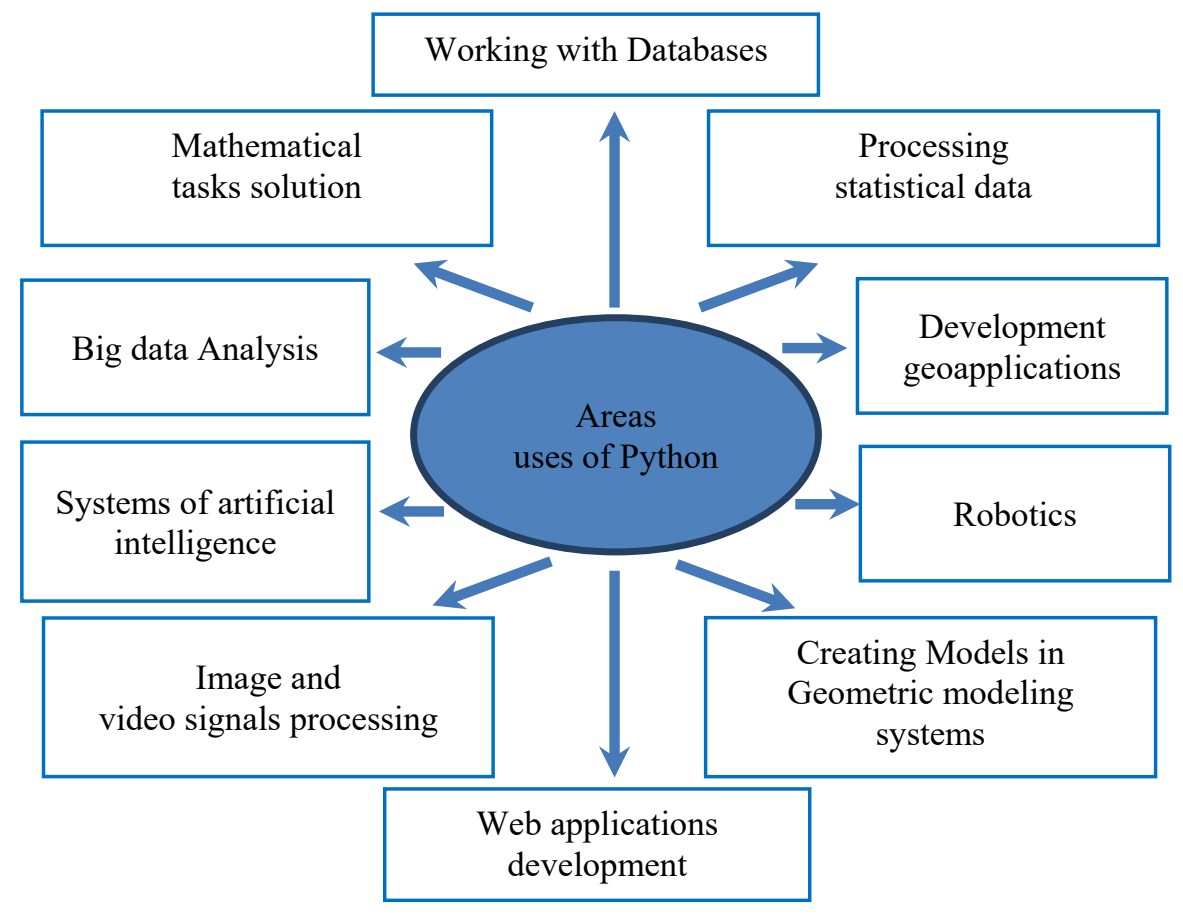

Fig. 1. Examples of Python usage areas.

Thus, the Python language allows to lay the foundations of systems elements development for technological objects control, controllers programming, which is especially important for students of machine-building directions.

3. Elements of development and software modules integration within the framework of automation systems. Any automation information system contains its own tools or integration mechanism with external software development tools, such as Application Programming Interface (API), which allows to adapt the software product to specific operating conditions and the range of tasks to be solved. This section is devoted to the development of the module of integration of the software product "COMPAS" with the software module implemented in any of the above programming languages in order to calculate mass-geometric object characteristics according to its geometric model formed in the CAD system. 
4. Bases of mathematical modeling. Operation of technical mechanisms, technological equipment can be described by means of mathematical models using such concepts as numerical methods of integration, differentiation, decomposition of functions into rows, etc.

Special attention in modern research on the prospects of engineering education is paid to mathematical training of students $[10,11,12]$. In professional activity there is demand for mathematical competence, knowledge of engineering sciences, as well as the ability to share them for technical tasks, considering that many previous manual operations are now replaced by technologies [13]. At the same time, the special importance for professional formation of the engineer of interdisciplinary courses using knowledge of mathematical methods in research [14] is stressed.

The inclusion of a section on mathematical modulation in the content of the "Information technologies in professional activity" discipline seemed relevant and appropriate. The purpose of this section study is to provide students with tools of specialized software for additional mathematical research. Among the packages are the following.

- Sage is a computer algebra system used in both mathematics and other fields of science, technology, engineering $[15,16]$. Sage is based on the Python programming language, so using the package is a logical extension of the previous section.

- Maxima - universal and quite powerful system of computer (symbolic) mathematics.

- MATLAB - a package that can be used to solve technical problems in further training $[17,18]$.

Application of specialized packages (Sage, Maxima, MATLAB) allows to make more visible the process of formation of corresponding mathematical models.

5. Bases of imitating modeling. The use of modern simulation systems allows to use already ready-made libraries of units for simulation of electric power, mechanical and hydraulic systems, as well as to use a developed model-oriented approach in the development of control systems, digital communication facilities and real-time devices. Using the example of Simulink, this section provides a solution to the problems of modeling real technical systems consisting of a limited set of sensors and actuators.

6. Method of design training. The formation of competences that will allow students to cope with the above-mentioned challenges in the development of machine-building production is impossible without close interweaving of theoretical and practical stages of training. Applying the project method to improve the efficiency of the educational process is not a new topic. However, in conditions of mass application of information technologies, transition to digital production, its application for obtaining qualitative result of training seems extremely promising. The discipline provides for the implementation of a project that includes tasks under a number of sections.

Project assignments vary depending on the direction of training and the level of training of students.

Option 1. Perform tasks in the CAD system, including using the API.

The project content includes the following tasks.

Task 1. Bases of three-dimensional modeling.

- Create a part 3D model (from a catalog) in the CAD system (for example, Compas 3D). An example of the implementation is shown in Fig. 2. 


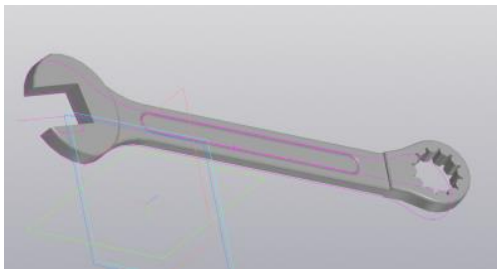

(a)

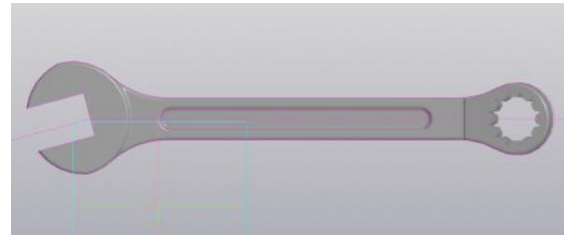

(c)

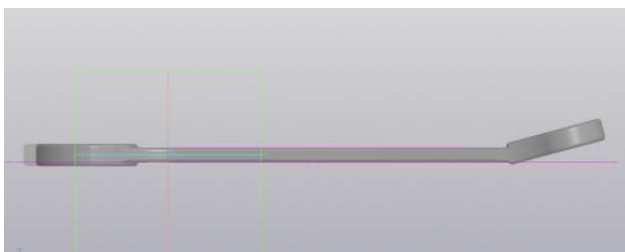

(b)

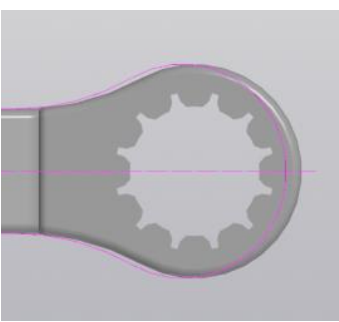

(d)

Fig. 2. A three-dimensional model of the key constructed using sketches. (A 3D key model built using sketches.) (a) General view, (b) Side view, (c) Main type, (d) Element.

The model uses a sheet body for ease of bending $(a-b)$. The volume was created using various methods of extrusion, such functions as mirror array and plane offset were used to build the protruding parts of the key.

- Implement parametric part modeling using at least 3 parameters (dimensions). An example of this is shown in Fig. 3.

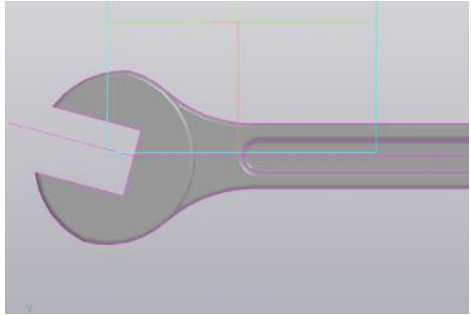

(a)

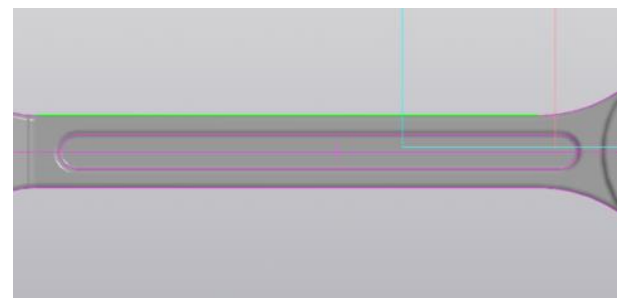

(b)

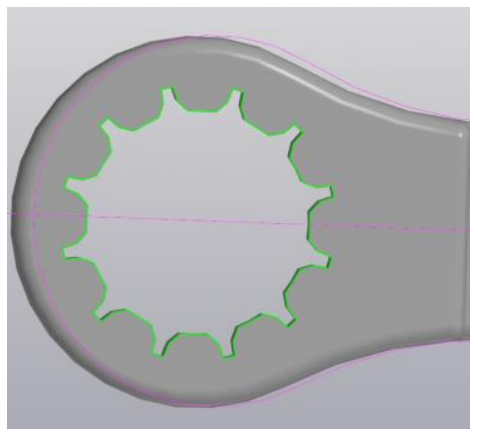

(c)

Fig. 3. Parametric modeling of a part. (a) Changing the tilt of the open mouth, (b) Change the length of the recess, (c) The diameter changes. 
Task 2. Creation of design documentation.

- Creates the part drawing in the CAD system to the standards.

- Creation of the specification.

Task 3. Creation of the simplified image.

- Draws a simplified image of the three main views of the part according to the part drawing from task 2 .

- Build a simplified image in the Lazarus development environment (Delphi, Borland Developer Studio or other).

Task 4. Development of a software module to solve engineering problems.

Software module requirements:

- implementation of CAD, CAM, SAE functions;

- work with more than 1 form;

- ergonomic interface (design, usefulness, simplicity, intuition);

- work with external software;

- use of standard user functions;

- error handling.

A separate required competence of engineers - project management, solving tasks between several working groups, which requires interaction of all participants of the project. The use of PDLM packages is not available in educational institutions due to their high cost. A possible solution is a combination of project training methods, cloud software that creates a simulation of professional context [19].

CAD 3D modeling tasks are successfully used to develop student creativity [20]. Students early familiarity with 3D CAD technology will help them better master the design skills they will need in a professional career [21].

Option 2. Perform tasks from different sections (Fig. 4).

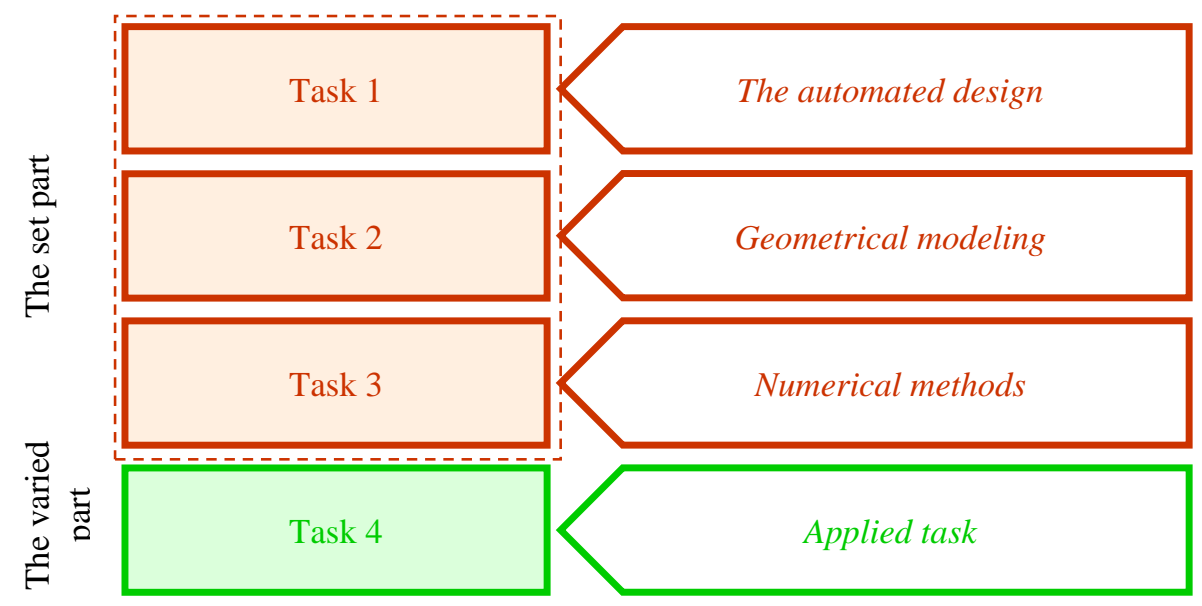

Fig. 4. Version of the project content.

The complexity of the project is determined by the set of tasks and the level of implementation of each task. The setting of each task contains a basic part - mandatory and extended, allowing students to realize creative potential. 
Task 1. The automated design.

Base part: creating a 3-D image of a part (of a detail;); creation of design documentation; A simplified representation of the part (of the detail) for the form from which the part will be made.

Advanced part: development of a software module for solving design problems (for example, using the COMPAS-3D API).

For an example of performing a task, see Fig. 5.

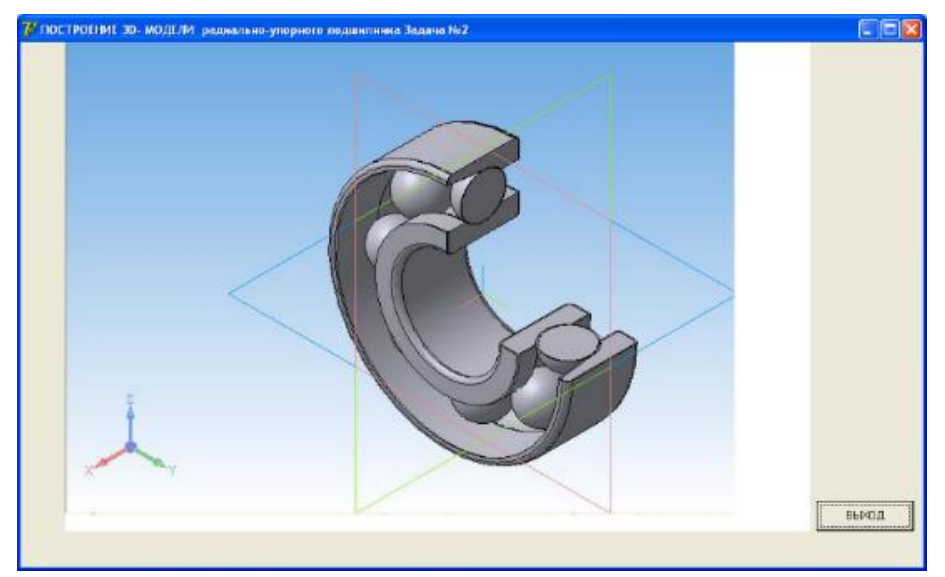

Fig. 5. Examples of implementation of the task in the automated design system.

Task 2. Geometrical modeling. It is proposed to develop a program for modeling and converting geometric objects using visual programming tools.

Base part: creating mathematical models of geometric entities (uses theoretical material from sections triangulation of surfaces, matrices of linear transformations, projection of the model on a plane, quaternions); development of algorithm for figure modeling, creation of form - user interface of software module; writing program code for modeling geometric objects with possibility of entering length of shape faces; writing program code to convert shapes (moving shapes; rotation around axes OX, OY, OZ with possibility of entering rotation angle; scaling with the ability to enter a scaling factor; hatching or filling one of the faces of the polyhedron), writing code to calculate the volume of figures with the possibility of displaying the result.

Extended Part: implement the ability to fit one shape into another; drawing object intersections.

An example of a task implementation is shown in Fig. 6. 


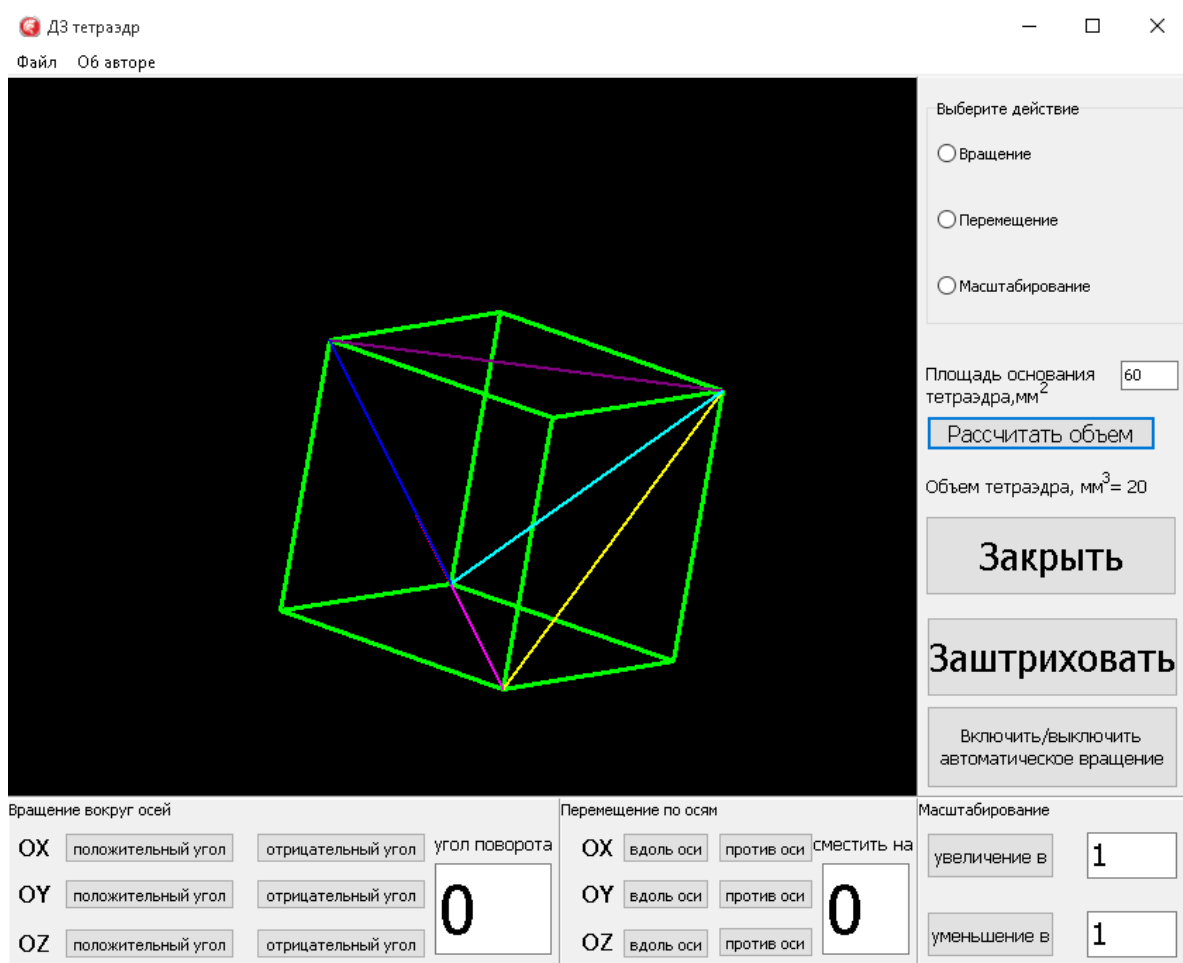

Fig. 6. An example of an implementation of a geometric modeling task.

Table 1. Contains of Figure 6.

\begin{tabular}{|c|c|}
\hline Phrase in Russian & English equivalent \\
\hline ДЗ тетраэдр & Homework tetrahedron \\
\hline Файл & File \\
\hline Об авторе & About the author \\
\hline Выберите действие & Select an action \\
\hline Вращение & Rotation \\
\hline Перемещение & Moving \\
\hline Масштабирование & Scaling \\
\hline Площадь основания тетраэдра, мм ${ }^{2}$ & Tetrahedron base area, $\mathrm{mm}^{2}$ \\
\hline Рассчитать объем & Calculate volume \\
\hline Объем тетраэдра, мм $^{3}$ & Tetrahedron volume, $\mathrm{mm}^{3}$ \\
\hline Закрыть & Close \\
\hline Заштриховать & Shade \\
\hline $\begin{array}{r}\text { Включить/выключить } \\
\text { автоматическое вращение }\end{array}$ & Turn auto rotation on / off \\
\hline Вращение вокруг осей & Rotation around axes \\
\hline Положительный угол & Positive angle \\
\hline Отрицательный угол & Negative angle \\
\hline Угол поворота & Angle of rotation \\
\hline Перемещение по осям & Axis movement \\
\hline Вдоль оси & Along the axis \\
\hline Против оси & Against the axis \\
\hline Сместить на & Move to \\
\hline Увеличение в & Increase in \\
\hline Уменьшение в & Decrease in \\
\hline
\end{tabular}


Task 3. Numerical methods, approximate calculations. It is proposed to develop a program in one of the considered languages for approximate calculations of differential and integral characteristics of analytically specified function, approximate solution of nonlinear and differential equations.

Basic unit:

- approximate calculation of a certain integral on a given segment (using methods of rectangles, trapezoids, parabols); checking the result according to Newton-Leibniz formula (for analytically integrated function); comparing results obtained by different methods; Using the program for a function that is not analytically integrated;

- is the approximate calculation of a derivative of an analytically defined function at a given point;

- approximate solution of nonlinear equation $f(x)=0$ by one of methods (method of division in half, method of iterations, method of chords, method of tangents, combined method) with condition of finding all roots on specified interval;

- approximate solution of differential equation $y^{\prime}=f(x, y)$ by one of methods (Euler method, Runge-Kutt method); checking the obtained result with the help of analytical solution of differential equation, using the considered mathematical packages.

Extended part: approximate calculation of a certain integral at a given segment by preliminary decomposition into Taylor series with selection of decomposition point; increasing the number of methods used, comparing results obtained by different methods, drawing a graph of a function specified in table (numerical methods) and an analytical solution.

Task 4. The solution of the application problem is the student's choice of one of the preexisting tasks, or the approval of the individual task.

In the table 2 shows the allocation of time to study each of the sections presented.

Table 2. Content of discipline.

\begin{tabular}{ccc}
\hline Section & $\begin{array}{c}\text { Number of } \\
\text { occupations, hour }\end{array}$ & $\begin{array}{c}\text { Share from total } \\
\text { amount }\end{array}$ \\
\hline Algorithmization and programming & 16 & $20,00 \%$ \\
Python Programming & 10 & $12,50 \%$ \\
$\begin{array}{c}\text { Development and interface of software } \\
\text { modules within automation systems }\end{array}$ & 20 & $25,00 \%$ \\
$\begin{array}{c}\text { Development and interface of software } \\
\text { modules within automation systems }\end{array}$ & 6 & $7,50 \%$ \\
Bases of imitating modeling & 12 & $15,00 \%$ \\
Project & 16 & $20,00 \%$ \\
\hline
\end{tabular}

\section{Conclusions of the research and prospects for further development}

In the proposed embodiment, discipline allows to motivate students for the final result, to integrate individual components of the course, provides advantages of combining traditional and project training.

It is planned to develop an e-learning course, which comprehensively uses modern capabilities of information technologies for individualization and improvement of the quality of education, with content that takes into account the peculiarities of the content of certain directions of training. 


\section{References}

1. J. Trevelyan, Transitioning to engineering practice, European Journal of Engineering

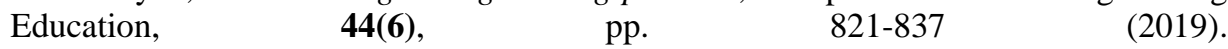
https://doi.org/10.1080/03043797.2019.1681631.

2. R. Razdan, R. Polanco, Z. Ackerman, X. Vidot, D. Razdan, GANDALF: A real-world solution to the "soft Skills" problem for engineering careers, IEEE Technology and Engineering Management Conference, TEMSCON (2019). 8813665. DOI: 10.1109/TEMSCON.2019.8813665.

3. N.I. Sidnyaev, Modern problems of elite engineering education, Mechanical engineering and engineering education, № 3, 64 - 74 (2014).

4. D.V. Kurennov, E.I. Katz, G.L. Kovács, Swept volume evaluation using the BSP-dexel representation for the 5-axis CNC machining simulation, Pollack Periodica, 14(1), pp. 59-66 (2019). https://doi.org/10.1556/606.2019.14.1.6.

5. R. Gayanov, K. Mironov, R. Mukhametshin, A. Vokhmintsev, D. Kurennov, Transportation of small objects by robotic throwing and catching: applying genetic programming for trajectory estimation, IFAC-PapersOnLine, Volume 51, Issue 30, pp. 533-537 (2018). https://doi.org/10.1016/j.ifacol.2018.11.271.

6. O.V. Savchenko, D.V. Kurennov, Description of the technique of pattern recognition and neural network formation in the conditions of multistage information processing, Information Technologies for Intelligent Decision Making Support (ITIDS'2016) Proceedings of the 4th International Conference, pp. 181-184 (2016).

7. S. Cass, The Top Programming Languages 2019 (2019) Retrieved from https://spectrum.ieee.org/computing/software/the-top-programming-languages-2019.

8. R. Fraanje, T. Koreneef, A. Le Mair, S. de Jong, Python in robotics and mechatronics education, 2016 11th France-Japan \& 9th Europe-Asia Congress on Mechatronics (MECATRONICS)/17th International Conference on Research and Education in Mechatronics (REM), pp. 014-019. IEEE June (2016). DOI: 10.1109/MECATRONICS.2016.7547108

9. A.B. Raju, S. Annigeri, Computing in engineering education: The current scenario, 2014 International Conference on Contemporary Computing and Informatics (IC3I), pp. 130-134. IEEE November (2014). DOI: 10.1109/IC3I.2014.7019770.

10. M. Nedaei, F. Radmehr, M. Drake, Exploring engineering undergraduate students' attitudes toward mathematical problem posing, Journal of Professional Issues in Engineering Education and Practice 145(4), 04019009 (2019). DOI: 10.1061/(ASCE)EI.1943-5541.0000418.

11. E.V. Kuzmina, N.G. Pyankova, N.Y. Naryzhnaya, Development of creative potential of students of engineering specialties within the framework of mathematical and information disciplines, D. Solovev (eds), Smart Technologies and Innovations in Design for Control of Technological Processes and Objects: Economy and Production. FarEastCon 2018, Smart Innovation, Systems and Technologies, vol 139. Springer, Cham (2019). https://doi.org/10.1007/978-3-030-18553-4_7.

12. D. Dias Rasteiro, V. Gayoso Martinez, C. Caridade, J. Martin-Vaquero, A. QueirugaDios, Changing teaching: Competencies versus contents, IEEE Global Engineering Education Conference, EDUCON, vol. 2018-April, 23 May 2018, pp. 1761-1765 (2018). DOI: 10.1109/EDUCON.2018.8363447. 
13. A. Munns, A study of competence in mathematics and mechanics in an engineering curriculum, European Journal of Engineering Education, 42 (6), pp. 1062-1075 (2017). https://doi.org/10.1080/03043797.2016.1259292.

14. J.A. Weliwita, S. Witharana, Amalgamate mathematical methods and engineering curriculum to uplift innovations, Advances in Science and Engineering Technology International Conferences, ASET 20188 June 2018, pp. 1-5 (2018). DOI: 10.1109/ICASET.2018.8376935.

15. G.V. Bard, Sage for Undergraduates, The American Mathematical Society, p. 362 (2015). ISBN-13: 978-1470411114.

16. P. Zimmermann, A. Casamayou, N. Cohen, G. Connan, T. Dumont, L. Fousse, F. Maltey, M. Meulien, M. Mezzarobba, C. Pernet, N. M. Thiéry, E. Bray, J. Cremona, M. Forets, A. Ghitza, H. Thomas, Computational Mathematics with SageMath. http://sagebook.gforge.inria.fr.

17. C. Vieira, A. J. Magana, A. Roy, M.L. Falk, Student explanations in the context of computational science and engineering education, Cognition and Instruction, 37(2), pp. 201-231 (2019). https://doi.org/10.1080/07370008.2018.1539738.

18. M.I. Szávuly, Á. Tóos, R. Barabás, B. Szilágyi, From modeling to virtual laboratory development of a continuous binary distillation column for engineering education using MATLAB and LabVIEW, Computer Applications in Engineering Education, 27(5), 1019-1029 (2019). https://doi.org/10.1002/cae.22119.

19. J.L. Saorín, J. de la Torre-Cantero, D.M. Díaz, V. López-Chao, Cloud-based collaborative $3 D$ modeling to train engineers for the Industry 4.0, Applied Sciences $\begin{array}{lllll}\text { (Switzerland), } & \mathbf{9 ( 2 1 )}, & \text { November } & 2019, & 4559\end{array}$ https://doi.org/10.3390/app9214559.

20. C. Carbonell-Carrera, J.L. Saorin, D. Melian-Diaz, J. de la Torre-Cantero, Enhancing creative thinking in STEM with 3D CAD modelling, Sustainability (Switzerland), 11 (21), November 2019, p. 6036 (2019). https://doi.org/10.3390/su11216036.

21. M. Planchard, 3D CAD: A plus for STEM education, Engineering Design Graphics Journal, 71 (2), pp. 1-4 (2007). 